\title{
Technical Assistance is Related to Improvements in the Food Pantry Consumer Nutrition Environment
}

\author{
Cassandra J. Nikolaus, $\mathrm{PhD}^{1}$; Caitlin Kownacki, $\mathrm{MS}^{2}$; Zaheeda Darvesh, MUP ${ }^{3}$; \\ Jennifer McCaffrey, $\mathrm{PhD}, \mathrm{MPH}^{2}$
}

\begin{abstract}
Objective: To assess changes in food pantries' consumer nutrition environment (CNE) after the provision of technical assistance.

Design: Pre-post study with 2 phases.

Setting: Staff completed observational assessments using the Nutrition Environment Food Pantry Assessment Tool (NEFPAT) at food pantries in an initial pilot phase. Then, staff conducted NEFPAT observations at pantries in Illinois statewide.

Participants: In the pilot phase, 6 staff assessed 28 pantries. In the statewide phase, 35 staff assessed 119 pantries.

Intervention: After completing an initial NEFPAT at each pantry, technical assistance was provided by staff to support changes in the pantries' CNE before another NEFPAT observation was completed.

Main Outcome Measure: Changes in the CNE, as assessed with the NEFPAT, when comparing preassessment and postassessment.

Analysis: Score differences were evaluated with paired $t$ tests.

Results: In the pilot phase, among 23 pantries with preassessment and postassessment data, 2 objectives on the NEFPAT observation increased significantly. In the statewide phase, among 66 pantries with preassessment and postassessment data, most NEFPAT objectives and the overall NEFPAT score $(22.12 \pm 8.16$ vs $28.20 \pm 7.14, P<0.001)$ significantly increased.

Conclusions and Implications: Technical assistance provided by Supplemental Nutrition Assistance Program Education implementing staff were related to improvements in the CNE of food pantries in Illinois. Future work should evaluate the association of these CNE changes with changes in behavior among pantry patrons.
\end{abstract}

Key Words: emergency food, food bank, food environment, food assistance, food insecurity (J Nutr Educ Behav. 2021;53:742-750.)

Accepted May 17, 2021. Published online June 30, 2021.

\section{INTRODUCTION}

Food insecurity is a priority nutrition issue in the US, occurring when a household has insufficient access to enough nutritious food because of economic or transportation limitations. Food insecurity is associated with chronic disease development, ${ }^{1}$ poor disease selfmanagement, ${ }^{2}$ diminished mental health, ${ }^{3}$ greater health care costs, ${ }^{4,5}$ and mortality. ${ }^{6,7}$ Although present among households in varying rates

\footnotetext{
${ }^{1}$ Institute for Research and Education to Advance Community Health, Washington State University, Seattle, WA

${ }^{2}$ Office of Extension and Outreach, University of Illinois at Urbana-Champaign, Urbana, IL

${ }^{3}$ The Center for Innovation in Teaching and Learning, University of Illinois at UrbanaChampaign, Champaign, IL

Conflict of Interest Disclosure: The authors have not stated any conflicts of interest.

Address for correspondence: Cassandra J. Nikolaus, PhD, Institute for Research and Education to Advance Community Health, Washington State University, 1100 Olive Way, Ste 1200, Seattle, WA 98101; E-mail: Cassandra.nikolaus@wsu.edu

(C) 2021 The Authors. Published by Elsevier Inc. on behalf of Society for Nutrition Education and Behavior. This is an open access article under the CC BY-NC-ND license (http:// creativecommons.org/licenses/by-nc-nd/4.0/)

https://doi.org/10.1016/j.jneb.2021.05.005
}

since national surveillance began in $1995,{ }^{8}$ food insecurity has risen dramatically during the current economic downturn, impacting an estimated 54 million US households in $2020 .^{9}$

A number of federal programs exist to address food insecurity and provide nutrition assistance. These include the Supplemental Nutrition Assistance Program (SNAP), the Special Supplemental Nutrition Program for Women, Infants and Children, the National School Lunch Program, and the Food Distribution Program on Indian Reservations, among others. ${ }^{10}$ However, these programs fall short in eradicating food insecurity in the US for 2 overarching reasons. First, households experiencing food insecurity may not meet eligibility criteria for these programs, ${ }^{11}$ which 
include income, employment, or other household characteristics. Second, individuals or households participating in these programs may not receive sufficient assistance to eliminate their food insecurity. ${ }^{12}$

Food pantries, also commonly referred to as food banks or food shelves, are usually private voluntary responses that attend to US households' food security needs by distributing free grocery items to individuals. The number of food pantries in the US rapidly increased during the 1980s, with many founders expecting they would provide emergency food on a short-term basis. ${ }^{13}$ However, studies suggest that longterm use of food pantries is not uncommon, ${ }^{14-17}$ and diet-sensitive conditions, such as obesity, diabetes, and high blood pressure, are prevalent among patrons. ${ }^{18,19}$ These conditions are precipitated by circumstances of poverty, limited access to nutritious foods, and other social determinants of health. ${ }^{20}$ Therefore, promotion of health and nutrition in food pantries is warranted. In line with these goals, the nutritional quality of food pantries' inventories can be monitored and improved, ${ }^{21,22}$ but other changes can be made to the setting and layout that patrons interact with-termed the consumer nutrition environment (CNE) - to encourage and support healthy food choices.

The CNE is comprised not only of the type and quantity of healthy foods available but also price, promotion, placement, and provision of nutrition information. ${ }^{23}$ Interventions focused on the CNE in lowincome settings have resulted in some positive changes in purchases and dietary intake. ${ }^{24}$ However, interventions have historically overlooked food pantries, taking place most frequently in grocery stores, corner stores, schools, worksites, and community centers. ${ }^{24,25}$

Research on the CNE in food pantry settings is an emerging area of inquiry. The majority of studies have been descriptive, showing that the minority of food pantries use client choice distribution models or have written nutrition policies. ${ }^{26,27}$ Furthermore, food pantries have significant barriers to creating curated CNEs, including limited storage space, ${ }^{28}$ attitudes and preferences of donors, ${ }^{29}$ and varying levels of external support. ${ }^{30}$ Despite these barriers, a handful of recent intervention studies have shown promise, indicating that pantries provided technical assistance have positive changes in their CNE or client food selections. ${ }^{31}$ -35 However, prior intervention findings have been based on limited samples.

The current study aims to fill a gap in the literature by leveraging data collected by Extension staff providing technical assistance to food pantries across Illinois for 4 years. Staff completed evaluations of the CNE at these food pantries as part of the implementation of the Supplemental Nutrition Assistance Program Education (SNAP-Ed) in Illinois. Assessments of the CNE were conducted while initiating relationships with food pantries (preassessment) and again after technical assistance was provided (postassessment) to evaluate the progress of the pantries in adopting policy, systems, and environmental strategies to promote health and nutrition. For purposes of this article, technical assistance is defined as the use of one's professional expertise to interpret preassessment data and provide facilitation of feasible $\mathrm{CNE}$ changes on the basis of each organization's assets and larger circumstances. The objective of the analyses presented here was to assess whether the provision of technical assistance by SNAP-Ed staff is associated with changes in the food pantries' CNE within Illinois.

\section{METHODS}

\section{Study Design}

This was a pre-post study with 2 phases. The pilot phase was conducted as a part of a larger multilevel, multimode, community-based assessment of Illinois' Extension-based nutrition education programming. ${ }^{36}$ The pilot phase was conducted from October, 2016 to October, 2018, wherein SNAP-Ed staff collected data from all food pantries identified within 3 regions in Illinois. During the pilot phase, SNAP-Ed staff provided feedback on the assessment processes and contributed to the creation of supporting materials and resources to facilitate the provision of technical assistance to food pantries. The statewide phase was conducted from January, 2017 to February, 2020, wherein staff, based on their geographic location, collected data from and provided technical assistance to food pantries across Illinois. This was followed by retrospective surveys of SNAP-Ed staff in August 2020 to provide contextual information about the Nutrition Environment Food Pantry Assessment Tool (NEFPAT) observations completed and assistance provided. Six staff conducted all NEFPAT observations in the pilot phase, whereas 35 staff assessed pantries in the statewide phase. The University of Illinois at Urbana-Champaign Institutional Review Board considered this study nonhuman subjects research because data were collected on the institutions and technical assistance processes, not about individuals and/or their personal experiences.

\section{Instrument}

Food pantry CNE observations were conducted using NEFPAT, which has established content validity and interrater reliability when used by SNAP-Ed implementing staff in Illinois. ${ }^{27}$ The NEFPAT includes 47 strategies to promote health and nutrition in the CNE, which are organized into 6 objectives: (1) increase client choice for nutritious options, (2) market and nudge healthful products, (3) provide various forms of fruits/vegetables, (4) provide various types of fruits/vegetables, (5) promote additional resources, and (6) plan for alternate eating patterns. Each strategy used by the pantry is scored as 1 , resulting in an overall score ranging from 0 to 47 . In addition, there are unscored aspects of the NEFPAT collected for each pantry to provide further characterization, which includes individuals served per month, distance from public transit, the sources of foods and funds, and whether the type of client served is restricted. A 1-hour webbased training video was completed by all SNAP-Ed staff to ensure consistent use and deployment of NEFPAT. 
This consistent use was confirmed with tests of interrater reliability. ${ }^{27}$

After the NEFPAT was originally published, stakeholder feedback led to a rearrangement of strategies within objectives 1 and 5 and minor changes to strategy wording. For example, the word "service" was dropped from the strategy: a policy is in place for proper food service safety, and the condition, "during the summer months" was dropped from the strategy: the pantry promotes or provides mobile markets during the summer months. In addition, the tool was updated by a graphic designer. These minor modifications have not impacted NEFPAT scoring procedures. Moreover, staff created supporting materials and implementation resources affiliated with each of the NEFPAT strategies. These included guides to transition to client choice distribution models, nutrition policy templates, examples of healthy donation lists, and ideas and resources for integrating healthy eating promotion materials in the pantry. Staff used the implementation resources when providing technical assistance in both phases of the study. The updated version of the NEFPAT and the implementation resources developed are available online, free of charge, in the SNAPEd toolkit. ${ }^{37,38}$

After the statewide phase, survey data were collected in August, 2020 from all SNAP-Ed staff that completed NEFPAT observations. The staff was asked to retrospectively report the reason that some pantries only completed a single NEFPAT evaluation. In addition, the staff was asked to provide information about the food pantries in which they had conducted multiple NEFPATs regarding the nature and amount of technical assistance they provided between these observations.

\section{Procedure and Intervention}

In the pilot phase, a comprehensive list of food pantries within 3 target regions was identified through online directories and community stakeholders. After the preassessment, technical assistance was provided by SNAP-Ed staff on the basis of the needs of the food pantry, and the pantry staff was instructed to complete a postassessment approximately 4-6 months after the initial NEFPAT observation. Each completed NEFPAT paper form was scanned and sent to a research assistant to enter the data into a database maintained for the pilot phase.

In the statewide phase, the SNAPEd staff identified food pantries within their target geographic region through community relationships and networks. Technical assistance was provided by SNAP-Ed staff on the basis of areas needing improvement from the NEFPAT preassessment, priorities of the pantries, and feasibility, as deemed by the pantry manager, for implementing the recommendation. Staff were instructed to complete a postassessment approximately 6-12 months after the initial NEFPAT observation or after recommendations were implemented. Data from each NEFPAT were entered by the staff into a database maintained for documenting all SNAP-Ed activities; this database was hosted on Qualtrics (Provo, UT) from 2016 to 2017 and then on the Program Evaluation and Reporting System from 2018 to the present day.

In both pilot and statewide phases, the staff collaborated with pantry staff and/or volunteers to identify the appropriate nature and amount of technical assistance on the basis of the pantry's capacity. In addition to the 1-hour training specific to the NEFPAT, all SNAP-Ed staff receives general training in providing technical assistance to organizations to implement policy, systems, and environmental changes. After completing the initial NEFPAT observation, SNAP-Ed staff would discuss results with pantry staff in person and suggest potential strategies to adopt or improve. On the basis of this discussion, the SNAP-Ed staff would consult the corresponding implementation resources for the strategies in the resource guide. ${ }^{37,38}$ If available, SNAP-Ed staff would also provide support by connecting pantries to external sources of funding or purchasing printed materials and display items. As 1 example, a SNAP-Ed staff might complete the NEFPAT preassessment, meet with the pantry staff to discuss results and gauge feasibility of possible approaches, create a strategy implementation plan, meet with the pantry staff twice more to provide guidance, identify an external funding or food resource for the pantry staff, and then complete a postassessment 6 months after the initial assessment. However, the strategies sought for implementation and intensity of guidance provided by the SNAP-Ed staff were dictated by pantry staff's interest, availability, and assistance desired.

\section{Data Analyses}

To characterize the samples in the 2 phases, mean and SD were calculated for continuous variables, whereas counts and percentages were constructed for categorical variables. The differences in NEFPAT observations from preassessment to postassessment were approximately normally distributed with minimal skewness and kurtosis close to 3 . Thus, paired sample $t$ tests were used to compare the differences in overall NEFPAT score and score on each of the NEFPAT's 6 objectives from preassessment to postassessment. All statistical analyses were conducted in STATA/MP (version 16.1, StataCorp, 2019), with a significance level set at alpha $=0.05$.

\section{RESULTS}

Twenty-eight pantries were assessed in the pilot phase. On average, pantries served approximately 700 individuals per month and had at least 2 sources of food and 1 source of funds (Table 1). Most pantries received food from a regional food bank and funds from a faith-based organization. Five pantries only completed a baseline NEFPAT observation (preassessment) in the pilot phase. Reasons for attrition included the pantry had closed $(n=3)$, the pantry was no longer interested in partnering with SNAP-Ed staff $(n=1)$, or unknown $(n=1)$. The remaining 23 pantries had paired pretechnical and posttechnical assistance observations. The time between assessments was, on average, 12.4 months but varied from 9.8 months to 24.3 months.

One hundred and nineteen pantries were included in the statewide 
Table 1. Characteristics of Food Pantries Included in 2 Phases of a Pre-Post Study of Consumer Nutrition Environments

\begin{tabular}{|c|c|c|c|c|c|c|c|c|}
\hline \multirow[b]{3}{*}{ Characteristic } & \multicolumn{4}{|c|}{ Three Region Pilot Phase } & \multicolumn{4}{|c|}{ Statewide Phase } \\
\hline & \multicolumn{2}{|c|}{$\begin{array}{c}\text { Baseline, } \\
n=28\end{array}$} & \multicolumn{2}{|c|}{$\begin{array}{l}\text { Baseline for } \\
\text { Paired Data, } \\
\qquad n=23\end{array}$} & \multicolumn{2}{|c|}{$\begin{array}{c}\text { Baseline, } \\
n=119\end{array}$} & \multicolumn{2}{|c|}{$\begin{array}{l}\text { Baseline for } \\
\text { Paired Data, } \\
\qquad n=66\end{array}$} \\
\hline & Mean & SD & Mean & SD & Mean & SD & Mean & SD \\
\hline Individuals served per month & 687.9 & 980.8 & 786.3 & $1,057.3$ & 848.4 & $1,114.4$ & 790.6 & 800.1 \\
\hline Distance from public transit, miles & 3.1 & 6.7 & 3.6 & 7.3 & 2.2 & 5.6 & 3.2 & 7.1 \\
\hline No. of food sources & 2.4 & 1.8 & 2.2 & 1.4 & 3.7 & 1.9 & 3.8 & 1.7 \\
\hline \multirow[t]{2}{*}{ No. of funding sources } & 1.4 & 0.7 & 1.5 & 0.7 & 3.0 & 1.6 & 3.0 & 1.5 \\
\hline & $\%$ & $\mathbf{n}$ & $\%$ & $\mathbf{n}$ & $\%$ & $n$ & $\%$ & $\mathbf{n}$ \\
\hline \multicolumn{9}{|l|}{ Sources of food } \\
\hline Food bank & 86 & 24 & 83 & 19 & 96 & 93 & 96 & 45 \\
\hline Faith-based organization & 36 & 10 & 35 & 8 & 49 & 47 & 49 & 23 \\
\hline Nonprofit organization & 21 & 6 & 22 & 5 & 29 & 28 & 34 & 16 \\
\hline Government & 7 & 2 & 0 & 0 & 26 & 25 & 23 & 11 \\
\hline Private donor & 43 & 12 & 44 & 10 & 60 & 58 & 64 & 30 \\
\hline Commercial business & 29 & 8 & 22 & 5 & 56 & 54 & 60 & 28 \\
\hline Community group & 21 & 6 & 17 & 4 & 41 & 40 & 47 & 22 \\
\hline Other & 0 & 0 & 0 & 0 & 12 & 12 & 11 & 5 \\
\hline \multicolumn{9}{|l|}{ Sources of funds } \\
\hline Food bank & 4 & 1 & 4 & 1 & 13 & 10 & 10 & 4 \\
\hline Faith-based organization & 75 & 21 & 70 & 16 & 82 & 64 & 88 & 35 \\
\hline Nonprofit organization & 18 & 5 & 22 & 5 & 33 & 26 & 35 & 14 \\
\hline Government & 4 & 1 & 4 & 1 & 13 & 10 & 10 & 4 \\
\hline Private donor & 29 & 8 & 35 & 8 & 76 & 59 & 78 & 31 \\
\hline Commercial business & 7 & 2 & 9 & 2 & 33 & 26 & 25 & 10 \\
\hline Community group & 0 & 0 & 0 & 0 & 39 & 30 & 43 & 17 \\
\hline Other & 4 & 1 & 4 & 1 & 13 & 10 & 13 & 5 \\
\hline Restricted clientele type & 36 & 10 & 39 & 9 & 64 & 66 & 60 & 30 \\
\hline
\end{tabular}

Note: Missing data for the pilot test at postintervention for individuals served $(n=1)$ and transit distance $(n=3)$. At baseline, missing data for the statewide implementation for individuals served ( $n=24$ in full sample and $n=16$ in paired sample), distance from public transit ( $n=48$ in the full sample and $n=35$ in the paired sample), sources of food $(n=22$ in the full sample and $n=19$ in the paired sample), sources of funds $(n=41$ in the full sample and $n=26$ in the paired sample), and audience restriction ( $n=16$ in the full sample and paired sample).

phase. On average, pantries served approximately 800 individuals per month and had $\geq 3$ sources of food and funds each (Table 1). Most pantries received food from a regional food bank and private donors, whereas funds were most frequently sourced from faith-based organizations and private donors. Fifty-three pantries only had a single NEFPAT observation completed for the preassessment. Reasons for attrition were broadly categorized in a retrospective report from staff as caused by: coronavirus disease 2019-related closures or limitations $(\mathrm{n}=12 ; 23 \%)$, SNAP-Ed staff left $(n=11 ; 21 \%)$, SNAP-Ed unit program priorities shifted $(n=7$; $13 \%)$, pantry leadership no longer interested in working with SNAP-Ed $(\mathrm{n}=7 ; 13 \%)$, pantry leadership did not respond to communication attempts $(n=4 ; 8 \%)$, additional NEFPAT(s) were completed and not recorded $(n=4 ; 8 \%)$, the pantry closed $(n=2 ; 1 \%)$, or the reason was unknown $(n=6 ; 11 \%)$. Sixty-six pantries had paired preassessment and postassessment data. The time between assessments was, on average, 9.2 months but varied between 1.6 months and 23.6 months.

Table 2 shows changes in NEFPAT scores preprovision and postprovision of technical assistance in both the pilot and statewide phases. When comparing pantries that did or did not continue with a postassistance observation, there were minimal descriptive differences in individual objective or overall NEFPAT scores. In the pilot phase, scores for objective 5 (promote additional resources) $(0.9 \pm 1.1$ vs $2.2 \pm 1.83, P=0.001)$ and objective 6 (plan for alternate eating patterns) $(1.0 \pm 0.4$ vs $1.2 \pm$ $0.7, P=0.007)$ on the NEFPAT increased from preassessment to postassessment, but there were no significant changes in other objectives or the overall NEFPAT score. In the statewide phase, there were significant increases in all but 1 of the NEFPAT objectives as well as the overall NEFPAT score $(22.1 \pm 8.2$ vs $28.2 \pm 7.1, P<0.001)$. There were no statistical differences in objective 3 


\section{NEFPAT Component}

Objective 1: increase client choice for nutritious options

Objective 2: market and nudge healthful products

Objective 3: provide various forms of fruits and/or vegetables

Objective 4: provide various types of fruits and/or vegetables

Objective 5: promote additional resources

Objective 6: plan for alternate eating patterns

Overall NEFPAT score

\section{NEFPAT Component}

Objective 1: increase client choice for nutritious options

Objective 2: market and nudge healthful products

Objective 3: provide various forms of fruits and/or vegetables

Objective 4: provide various types of fruits and/or vegetables

Objective 5: promote additional resources

Objective 6: plan for alternate eating patterns

Overall NEFPAT score

\section{Three Region Pilot Phase}

\begin{tabular}{|c|c|c|c|c|c|c|}
\hline \multicolumn{2}{|c|}{$\begin{array}{l}\text { Baseline, } \\
n=28\end{array}$} & \multicolumn{2}{|c|}{$\begin{array}{l}\text { Baseline for } \\
\text { Paired Data, } \\
\quad n=23\end{array}$} & \multicolumn{2}{|c|}{$\begin{array}{l}\text { Postassistance, } \\
\qquad n=23\end{array}$} & \multirow{2}{*}{$\begin{array}{l}\begin{array}{l}\text { Paired } \\
t \text { Test }\end{array} \\
P\end{array}$} \\
\hline Mean & SD & Mean & SD & Mean & SD & \\
\hline 2.4 & 1.5 & 2.5 & 1.5 & 2.8 & 1.7 & 0.39 \\
\hline 2.3 & 1.6 & 2.6 & 1.6 & 2.4 & 1.6 & 0.63 \\
\hline 3.9 & 1.6 & 4.1 & 1.7 & 3.7 & 1.1 & 0.36 \\
\hline 5.3 & 2.4 & 5.6 & 2.3 & 6.0 & 1.6 & 0.33 \\
\hline 0.9 & 1.2 & 0.9 & 1.1 & 2.2 & 1.8 & 0.001 \\
\hline 1.1 & 0.4 & 1.0 & 0.4 & 1.2 & 0.7 & 0.007 \\
\hline 15.9 & 6.1 & 16.7 & 6.1 & 18.3 & 4.7 & 0.16 \\
\hline
\end{tabular}

Statewide Phase

\begin{tabular}{|c|c|c|c|c|c|c|}
\hline \multicolumn{2}{|c|}{$\begin{array}{l}\text { Baseline, } \\
n=119\end{array}$} & \multicolumn{2}{|c|}{$\begin{array}{l}\text { Baseline for } \\
\text { Paired Data, } \\
\quad n=66\end{array}$} & \multicolumn{2}{|c|}{$\begin{array}{l}\text { Postassistance, } \\
\qquad n=66\end{array}$} & \multirow{2}{*}{$\begin{array}{c}\begin{array}{c}\text { Paired } \\
t \text { Test }\end{array} \\
P\end{array}$} \\
\hline Mean & SD & Mean & SD & Mean & SD & \\
\hline 3.7 & 1.6 & 3.7 & 1.8 & 4.5 & 1.8 & $<0.001$ \\
\hline 3.2 & 1.7 & 3.1 & 1.8 & 5.6 & 1.7 & $<0.001$ \\
\hline 4.1 & 1.7 & 4.2 & 1.7 & 4.6 & 1.5 & 0.06 \\
\hline 6.3 & 2.7 & 6.1 & 2.9 & 7.2 & 2.7 & $<0.001$ \\
\hline 3.7 & 2.3 & 3.5 & 2.2 & 4.4 & 2.0 & $<0.001$ \\
\hline 1.5 & 0.8 & 1.5 & 0.9 & 1.9 & 1.0 & $<0.001$ \\
\hline 22.5 & 7.8 & 22.1 & 8.2 & 28.2 & 7.1 & $<0.001$ \\
\hline
\end{tabular}

NEFPAT indicates Nutrition Environment Food Pantry Assessment Tool.

Note: Scores for objectives $1-3$, and 5 ranged from $0-8$, whereas scores ranged from $0-10$ for objective 4 and $0-5$ for objective 6. Paired $t$ test compared the mean values for each component at baseline and postassistance assessments for the paired data from the pilot phase $(n=23)$ and statewide phase $(n=66)$.

(provide various forms of fruits/vegetables) scores from preassessment to postassessment $(4.2 \pm 1.7$ vs $4.6 \pm$ 1.5; $P=0.06)$.

Supplementary Tables 1 and 2 show the scores for each strategy within the 6 NEFPAT objectives on the preassessment and postassessment for the pilot and statewide phases, respectively, to characterize the CNE at baseline and describe specific changes that happened from preassessment to postassessment. At baseline, among pantries in the pilot phase, some of the least common strategies in place at pantries were a written nutrition policy $(14 \%, n=4)$, provision of nutrition education to food pantry volunteers $(4 \%, n=1)$, and provision of culturally diverse foods to clients $(0 \%, \mathrm{n}=0)$. In the pilot, changes from preassessment to postassessment were most quantitatively pronounced for the use of bundling ( $0 \%$ vs $17 \%$ ), provision of nutrition education to clients $(17 \%$ vs $44 \%$ ), promoting or providing mobile markets (0\% vs 39\%), providing gardening resources (9\% vs 30\%), provision of employment assistance information (9\% vs $22 \%$ ), and provision of educational or self-improvement resources (0\% vs $30 \%$ ). In the statewide phase, the presence of a formal nutrition policy $(41 \%, n=43)$, provision of nutrition education to food pantry volunteers $(7 \%, \mathrm{n}=7)$, and provision of culturally diverse foods $(16 \%, n=17)$ at the preassessment were quantitatively greater than among pantries included in the pilot phase but were still limited. In the paired data from the statewide phase, some of the most pronounced changes from preassessment to postassessment included the food pantry offering all 5 food groups (46\% vs $68 \%$ ), encouraging nutritious donations (31\% vs 58\%), seeking donations from local gardeners/farmers ( $27 \%$ vs $42 \%$ ), offering healthy recipes (37\% vs $86 \%$ ), display of healthy eating promotional materials $(17 \%$ vs $73 \%$ ), use of supporting promotional information with shelf tags (6\% vs $58 \%$ ), provision of fresh fruits or vegetables (75\% vs $96 \%)$, and labeling a section of the pantry for foods that meet specific dietary restrictions ( $0 \%$ vs $20 \%$ ).

\section{DISCUSSION}

This study aimed to assess whether the provision of technical assistance by SNAP-Ed staff is associated with 
changes in the food pantries' CNE within Illinois. Results suggest that technical assistance provided by Extension staff is related to improvements in food pantries' CNE, as assessed with the NEFPAT. Although a control group would strengthen the findings, these results support the value that trained SNAP-Ed implementation staff can provide in improving the CNE in organizations serving clientele at high risk of food insecurity. Furthermore, the strategylevel information gleaned from NEFPAT observations across the state of Illinois illuminated the strategies most frequently adopted and those that may require additional resources to change in food pantries.

These findings add to the emerging literature on CNE-based interventions in food pantry settings. Recently, the Racial and Ethnic Approaches to Community Health program in Arkansas showed that foods provided to clients at 3 pantries were improved after supports to change the CNE were provided. ${ }^{33}$ However, these pantries did not employ client choice distribution models, and improvements to the foods distributed largely reflect changes to donors' behaviors. As an early case study, the Rainbow of Colors Choice Pantry Model was used by Ohio State University Extension to support 7 pantries in implementing client choice models and promoting nutrition through color-coded displays. ${ }^{31}$ The Voices for Food project showed a significant increase in CNE changes among 12 pantries provided coaching by Extension staff, in comparison with control pantries provided resources but no coaching. ${ }^{32}$ However, no details about the specific CNE changes adopted by pantries in these studies were reported. A recent pilot study of the SuperShelf intervention is 1 exception, describing implementation fidelity of CNE changes in 2 pantries that were provided coaching and support by Extension staff for 2 -4 months. ${ }^{35}$ In contrast to the prior literature, the current study provides specific CNE strategy-level information while being based on real-life adoption by the SNAP-Ed staff that was provided training on the NEFPAT and then allowed to independently offer technical assistance as determined by the partnership with the collaborating food pantry.

The nature of CNE changes that pantries implemented in the current study was informative. In the pilot phase, some of the greatest changes were observed for objective 5 (promote additional resources on the NEFPAT). It is possible that changes in this area of the NEFPAT are simpler to implement by providing information about relevant resources on a bulletin board or the staff conducting the observation also providing nutrition education at the pantry location. In contrast, the statewide phase indicated that changes from preobservation to postobservation were significant for the NEFPAT score overall and all objectives within the NEFPAT, except for objective 3, which focuses on providing fruits and vegetables in various forms (fresh, canned, frozen, dried, and juice). It was uncommon to have frozen or dried fruits and vegetables that met fat, sodium, and sugar requirements. Modifying this aspect of the CNE may be more difficult to change because much of the inventory at food pantries is donated. The SNAP-Ed staff works with pantries to provide a list of suggested foods to donors, but even if healthy frozen vegetables or dried fruit with no added sugar is explicitly listed, donors need to have the nutrition literacy and personal motivation to identify foods that meet these criteria. Differences in CNE changes resulting from the pilot and statewide phases could be a product of differing sample size and the statistical power provided or may reflect increased familiarity among SNAP-Ed staff with the NEFPAT and the library of supplemental resources that were created to support SNAP-Ed staff in providing technical assistance ${ }^{38}$ created during the pilot phase.

Results of the strategy-level assessments in the current study provide new insights into the CNE of the food pantries in Illinois. In both phases, the minority of pantries had a written nutrition policy at preassessment and postassessment. This is in line with prior literature indicating that a minority of food pantries have formal written policies, ${ }^{26,39,40}$ despite their perceived value by stakeholders. $^{41,42}$ In the current study, there was an increase in the adoption of nutrition policies after the provision of technical assistance, but it was only among a handful of pantries. Development of nutrition policies in the food pantry settings may be one of the more difficult CNE attributes to modify as it requires buy-in among food pantry staff and volunteers, takes time to create a policy specific to the pantry's circumstances, and can be hindered by the larger food system that the pantry resides within. Provision of nutrition training for pantry volunteers was also uncommon in the current study. Providing nutrition training to food pantry volunteers and staff has great potential for diffusion of information to clientele. ${ }^{43}$ In a survey of pantry personnel in Oklahoma, volunteers were interested in receiving training of this nature. ${ }^{40}$ Finally, few pantries in the sample provided culturally diverse foods. Providing foods that meet a variety of clients' cultural preferences not only shows awareness and respect for the diversity of clientele but also allows more clients to integrate items from the food pantry into familiar and desirable meals. ${ }^{44}$ In contrast, CNE strategies within objective 2 (market and nudge healthful products) and objective 5 (promote additional resources of the NEFPAT) were common areas in which pantries implemented changes between preassessment and postassessment. These objectives focus on changing the display of items and information available at food pantries, which may be simple for SNAP-Ed staff to provide assistance. Percent of pantries that made changes for strategies such as client choice or use of a shopping style distribution model was less pronounced, which likely reflects the complexity of implementing these CNE changes and could be related to readiness for change among food pantry staff or time invested by SNAP-Ed staff.

The time between assessments is likely related to $\mathrm{CNE}$ changes in food pantries. In the current study, assessments were often completed 12 months or less apart. In contrast, prior studies that have assessed CNE 
changes in food pantries often assessed changes $\geq 1$ years after baseline. ${ }^{32,33}$ As each study has employed different measures of CNE change, direct comparisons of how these varying periods between observations relate to the degree of $\mathrm{CNE}$ changes adopted are unknown. Furthermore, no studies have assessed whether and to what degree CNE changes are sustained after technical assistance is no longer regularly provided by external staff. These areas of inquiry would be valuable in guiding future SNAP-Ed staff implementation of CNE change in food pantries.

Given the high prevalence of chronic diet-related disease and food insecurity among food pantry clientele, improving the CNEs of food pantries provides a prime opportunity to promote public health. However, CNE-based interventions in food pantries are just one of many approaches. In the food pantry setting, the FreshPlace intervention incorporated CNE changes alongside 1-on-1 motivational interviewing for clientele, resulting in significant improvements in dietary patterns and self-sufficiency. ${ }^{45}$ Food pantries can also serve as venues for implementation of ancillary interventions, such as trauma-informed financial empowerment programming. ${ }^{46}$ Food pantries are a unique source of food assistance that do not regularly employ the same eligibility criteria employed by many federal sources of aid. However, almost half of food pantry users also receive SNAP benefits, ${ }^{11}$ and changes to SNAP, such as increasing benefit allotments or accounting for geographic variability in food prices, $^{12,47}$ could also improve public health. ${ }^{48}$ Some food insecure individuals find both food pantries and SNAP stigmatizing to use, ${ }^{49}$ and interventions to promote food security may need further tailoring to consider these experiences.

This study should be interpreted with consideration of its limitations. First, there was no control group. It was not feasible for staff to conduct assessments without providing technical assistance. Therefore, it was not possible to compare CNE changes in the current sample with a sample of pantries that were not provided technical assistance. Second, there was substantial attrition among pantries in the statewide phase of the study. Though these pantries did not vary considerably on the characteristics observed on their initial NEFPAT observation, it is possible that these pantries differed from those who completed both preassessment and postassessment in unobserved ways. As 1 example, it is possible that pantries that did not complete a postassessment were not receptive to the SNAP-Ed staff's technical assistance and could have had no or less CNE change than pantries that completed both preassessment and postassessment. However, almost a quarter of the missing follow-up assessments were attributed to closures resulting from the coronavirus pandemic in 2020, which has had substantial impacts on food pantry operations and CNE that are outside of the scope of the current paper. Third, given the pragmatic context of this study, the SNAP-Ed staff had autonomy over the nature and amount of technical assistance they provided. Study staff attempted to retrospectively collect survey data from the SNAP-Ed staff on technical assistance provision but concerns about recall accuracy given the amount of time that elapsed and the high rate of staff turnover decreased confidence in the validity of this data. Fourth, given the small sample sizes, the seasonality of assessments was not controlled for in analyses. However, seasonality is expected to have a negligible impact on results, given the limited and flexible strategies assessing inventory of the food pantry in the NEFPAT assessments. Finally, the implications of the current study are limited by the restriction to pantries in a single midwestern state and the lack of clientele diet or food selection data.

\section{IMPLICATIONS FOR RESEARCH AND PRACTICE}

This study sought to understand the magnitude and nature of CNE changes in food pantries across
Illinois after being provided technical assistance by SNAP-Ed implementing staff. Evidence suggests technical assistance leads to changes in the CNE of food pantries, but evidence would be stronger with a comparison group. Promotion of healthy foods and ancillary resources and the adoption of nutrition-focused policies and practices in food pantries were increased by SNAP-Ed staff. Further research in this area could advance the understanding of CNE changes in food pantries by including a control or waitlist group, assessing intervention intensity, and comparing how changes vary over varying periods. Findings can be directly employed by SNAP-Ed staff or others working to support food pantry CNE improvements. Strategies of interest to SNAP-Ed staff may include implementation of simple environmental nudges, such as bundling of healthy foods into a meal idea or provision of recipes highlighting healthy options. In addition, when engaging with highly motivated stakeholders, could focus on more complex efforts like the development of nutrition policies or identifying additional sources of healthy foods. Ultimately, the impact of these CNE changes on clients' selection and consumption behaviors should be investigated

\section{ACKNOWLEDGMENTS}

This material is based, in part, on work that is supported by the US Department of Agriculture North Central Nutrition Education Center of Excellence. The study funding source had no role in study design, collection, analysis, and interpretation of data, writing the report, and the decision to submit the report for publication. The authors would like to thank the numerous food pantry and SNAP-Ed staff who made this research possible.

\section{SUPPLEMENTARY DATA}

Supplementary data related to this article can be found at https://doi. org/10.1016/j.jneb.2021.05.005. 


\section{REFERENCES}

1. Laraia BA. Food insecurity and chronic disease. Adv Nutr. 2013;4:203-212.

2. Flint KL, Davis GM, Umpierrez GE. Emerging trends and the clinical impact of food insecurity in patients with diabetes. J Diabetes. 2020;12:187-196.

3. Jones AD. Food insecurity and mental health status: A global analysis of 149 countries. Am J Prev Med. 2017;53:264-273.

4. Men F, Gundersen C, Urquia ML, Tarasuk V. Food insecurity is associated with higher health care use and costs among Canadian adults. Health Aff (Millwood). 2020;39:1377-1385.

5. Berkowitz SA, Basu S, Gundersen C, Seligman HK. State-level and countylevel estimates of health care costs associated with food insecurity. Prev Chronic Dis. 2019;16:E90.

6. Walker RJ, Chawla A, Garacci E, et al. Assessing the relationship between food insecurity and mortality among U.S. adults. Ann Epidemiol. 2019;32: 43-48.

7. Men F, Gundersen C, Urquia ML, Tarasuk V. Association between household food insecurity and mortality in Canada: a population-based retrospective cohort study. CMAJ. 2020;192:E53E60.

8. Coleman-Jensen A, Rabbitt MP, Gregory CA, Singh A. Household Food Security in the United States in 2019. US Department of Agriculture, Economic Research Service; 2020.

9. Gundersen C, Hake M, Dewey A, Engelhard E. Food insecurity during COVID-19. Appl Econ Policy. 2021;43: 153-161.

10. Aussenberg RA, Colello KJ, Billings KC. Domestic Food Assistance: Summary of Programs. Congressional Research Service; 2019.

11. Waxman E, Joo N, Gonzalez D. Who Is Accessing Charitable Food in America? Urban Institute; 2019.

12. Christensen G, Bronchetti ET. Local food prices and the purchasing power of SNAP benefits. Food Policy. 2020;95:101937.

13. Poppendieck J. Dilemmas of emergency food: a guide for the perplexed. Agric Hum Values. 1994;11:69-76.

14. Daponte BO, Lewis GH, Sanders S, Taylor L. Food pantry use among lowincome households in Allegheny County, Pennsylvania. J Nutr Educ. 1998;30:50-57.
15. Kaiser ML, Cafer AM. Exploring longterm food pantry use: differences between persistent and prolonged typologies of use. J Hunger Environ Nutr. 2016;12:46-63.

16. Paynter S, Berner M, Anderson E. When even the 'Dollar Value Meal' costs too much: food insecurity and long term dependence on food pantry assistance. Public Admin Q. 2011;35:26-58.

17. Holmes E, Black JL, Heckelman A, et al. "Nothing is going to change three months from now": a mixed methods characterization of food bank use in Greater Vancouver. Soc Sci Med. 2018;200:129-136.

18. Robaina KA, Martin KS. Food insecurity, poor diet quality, and obesity among food pantry participants in Hartford, CT. J Nutr Educ Behav. 2013;45:159-164.

19. Weinfield NS, Mills G, Borger C, et al. Hunger in America 2014. Feeding America; 2014

20. World Health Organization. A Conceptual Framework for Action on the Social Determinants of Health. World Health Organization; 2010.

21. Seidel M, Laquatra I, Woods M, Sharrard J. Applying a nutrient-rich foods index algorithm to address nutrient content of food bank food. I Acad Nutr Diet. 2015;115:695-700.

22. Simmet A, Depa J, Tinnemann P, Stroebele-Benschop N. The nutritional quality of food provided from food pantries: a systematic review of existing literature. J Acad Nutr Diet. 2017;117:577-588.

23. Glanz K, Sallis JF, Saelens BE, Frank LD. Healthy nutrition environments: concepts and measures. Am J Health Promot. 2005;19:330-333. ii.

24. Gittelsohn J, Trude A. Diabetes and obesity prevention: changing the food environment in low-income settings. Nutr Rev. 2017;75(suppl 1):62-69.

25. Seymour JD, Yaroch AL, Serdula M, Blanck HM, Khan LK. Impact of nutrition environmental interventions on point-of-purchase behavior in adults: a review. Prev Med. 2004;39(suppl 2): S108-S136.

26. Long CR, Narcisse MR, Rowland B, et al. Written nutrition guidelines, client choice distribution, and adequate refrigerator storage are positively associated with increased offerings of feeding America's detailed foods to encourage (F2E) in a large sample of Arkansas food pantries. J Acad Nutr Diet. 2019;120:792-803.e5.
27. Nikolaus CJ, Laurent E, Loehmer E, An R, Khan N, McCaffrey J. Nutrition Environment Food Pantry Assessment Tool (NEFPAT): development and evaluation. J Nutr Educ Behav. 2018;50:724-728. e1.

28. Campbell EC, Ross M, Webb KL. Improving the nutritional quality of emergency food: a study of food bank organizational culture, capacity, and practices. $J$ Hunger Environ Nutr. 2013;8:261-280.

29. Handforth B, Hennink M, Schwartz MB. A qualitative study of nutritionbased initiatives at selected food banks in the feeding America network. I Acad Nutr Diet. 2013;113:411-415.

30. Bush-Kaufman A, Barale K, Walsh M, Sero R. In-depth qualitative interviews to explore healthy environment strategies in food pantries in the Western United States. J Acad Nutr Diet. 2019;119:1632-1643.

31. Remley DT, Kaiser ML, Osso T. A case study of promoting nutrition and longterm food security through choice pantry development. J Hunger Environ Nutr. 2013;8:324-336.

32. McCormack LA, Eicher-Miller HA, Remley DT, Moore LA, Stluka SR. The development and use of an assessment tool to capture changes in the food pantry nutrition environment and system of food distribution. Transl Behav Med. 2019;9:962-969.

33. Long CR, Rowland B, McElfish PA. Intervention to improve access to fresh fruits and vegetables among Arkansas food pantry clients. Prev Chronic Dis. 2019;16:E09.

34. Wilson NLW, Just DR, Swigert J, Wansink B. Food pantry selection solutions: a randomized controlled trial in clientchoice food pantries to nudge clients to targeted foods. J Public Health (Oxf). 2017;39:366-372.

35. Caspi CE, Canterbury M, Carlson S, et al. A behavioural economics approach to improving healthy food selection among food pantry clients. Public Health Nutr. 2019;22:2303-2313.

36. Nikolaus CJ, Loehmer E, Jones A, An R, Khan NA, McCaffrey J. Use of survival analysis to predict attrition among women participating in longitudinal community-based nutrition research. $J$ Nutr Educ Behav. 2019;51:1080-1087.

37. UNC Center for Health Promotion and Disease Prevention. SNAP-Ed Toolkit. https://snapedtoolkit.org/. Accessed June 4, 2021.

38. Illinois Nutrition Education Programs. NEFPAT Technical Assistance and 
Resource Guide. University of Illinois Extension; 2019.

39. Helmick MJ, Yaroch AL, Parks CA, Estabrooks PA, Hill JL. Utilizing the REAIM framework to understand adoption of nutrition policies at food pantries across the USA. Transl Behav Med. 2019;9:1112-1121.

40. Wetherill MS, Williams MB, White KC, Li J, Vidrine JI, Vidrine DJ. Food pantries as partners in population health: assessing organizational and personnel readiness for delivering nutrition-focused charitable food assistance. J Hunger Environ Nutr. 2018; 14:50-69.

41. Shimada T, Ross M, Campbell EC, Webb KL. A model to drive researchbased policy change: improving the nutritional quality of emergency food. J Hunger Environ Nutr. 2013;8: 281-293.
42. Wetherill MS, White KC, Seligman HK. Nutrition-focused food banking in the United States: a qualitative study of healthy food distribution initiatives. J Acad Nutr Diet. 2019;119:16531665.

43. Remley DT, Gallagher T, McDowell J, Kershaw M, Lambea MC, MelgarQuinonez H. Extension's role in developing "Choice" food pantries in Southwest Ohio. J Extension. 2006;44: 6IAW5.

44. Remley DT, Zubieta AC, Lambea MC, Quinonez HM, Taylor C. Spanish- and English-speaking client perceptions of choice food pantries. J Hunger Environ Nutr. 2010;5:120-128.

45. Martin KS, Wu R, Wolff M, Colantonio AG, Grady J. A novel food pantry program: food security, self-sufficiency, and diet-quality outcomes. Am J Prev Med. 2013;45:569-575.
46. Phojanakong P, Welles S, Dugan J, Booshehri L, Brown Weida E, Chilton M. Trauma-informed financial empowerment programming improves food security among families with young children. J Nutr Educ Behav. 2020;52:465-473.

47. Research Healthy Eating. The Impact of Increasing SNAP Benefits on Stabilizing the Economy, Reducing Poverty and Food Insecurity Amid COVID-19 Pandemic. Robert Wood Johnson; 2020.

48. Gundersen C, Waxman E, Crumbaugh AS. An examination of the adequacy of Supplemental Nutrition Assistance Program (SNAP) benefit levels: impacts on food insecurity. Agric Resour Econ Rev. 2019;48:433-447.

49. Nikolaus CJ, Ellison B, Nickols-Richardson SM. College students' interpretations of food security questions: results from cognitive interviews. BMC Public Health. 2019;19:1282.

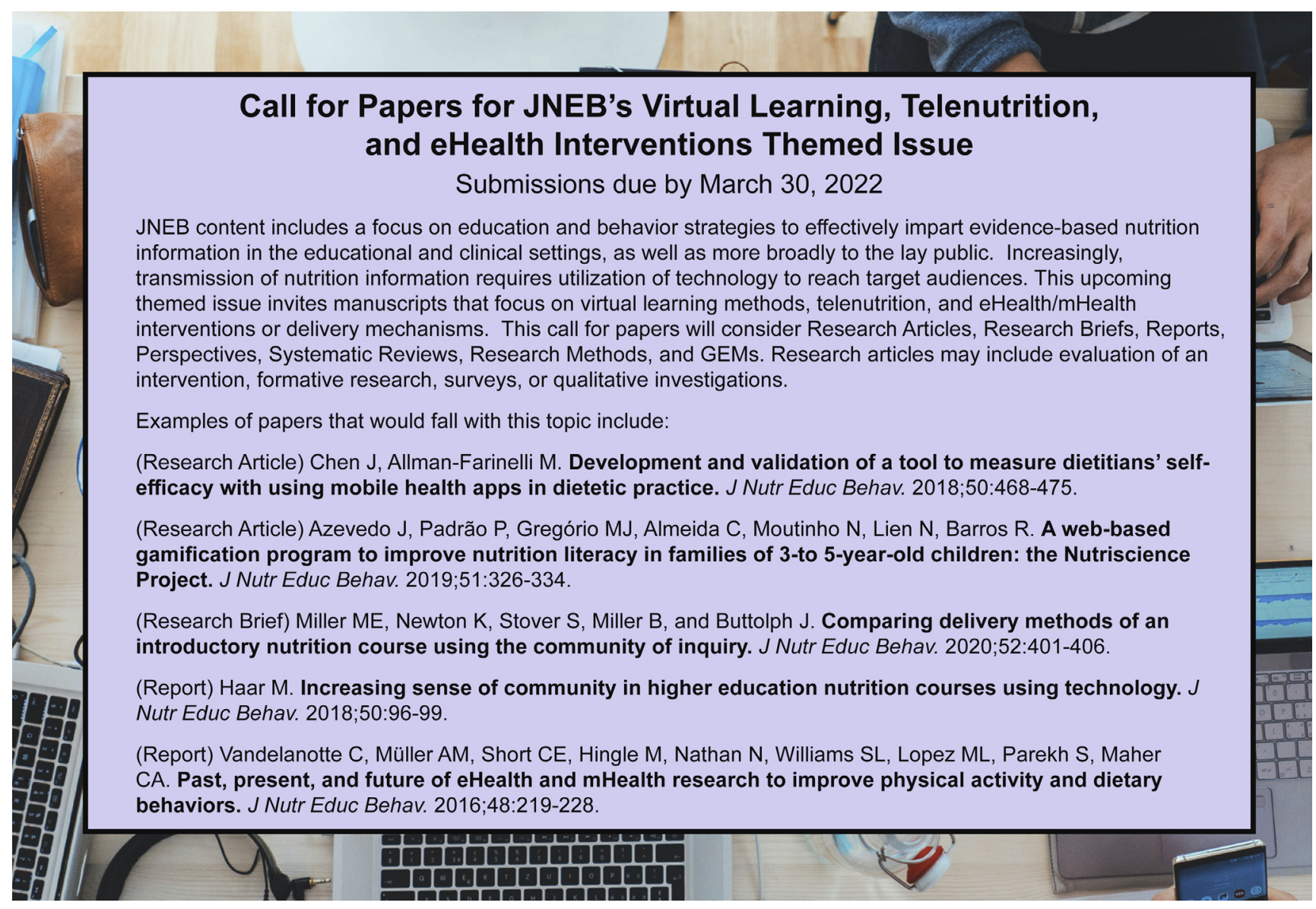

